\title{
Intercity Bus Passengers' Perception and Response to In-Vehicle Medication Drug Hawking
}

\author{
Allen Nnanwuba Adum \\ Department of Mass Communication, Nnamdi Azikiwe University, Awka, \\ Anambra State, Nigeria \\ Ogochukwu Ekwenchi \\ Department of Mass Communication, Nnamdi Azikiwe University, Awka, \\ Anambra State, Nigeria \\ Emeka Odogwu \\ Department of Mass Communication, \\ Nnamdi Azikiwe University, Awka, \\ Anambra State, Nigeria \\ Kobimdi Cordelia Umeh \\ Department of Mass Communication, \\ Nnamdi Azikiwe University, Awka, \\ Anambra State, Nigeria
}

\begin{abstract}
This study examined Nigerian intercity bus passengers' perceptions of in-vehicle medication drug hawking. It equally determined whether there was high patronage for vended drugs and why; and assessed the consumer views on the quality of hawked drugs and associated risks. An explanatory analysis was applied for the study. Structured interviews were completed by 300 respondents, selected using volunteer sampling of two parks in Onitsha commercial city, southeast Nigeria. Conclusively, the study revealed high patronage of hawked drugs, especially herbal medicines; most respondents (consumers) rated the quality of herbal medicine higher than Over-the-Counter (OTC) and prescription drugs. The study further established a strong link between patronage of hawked medication drugs and inhibiting factors to the use of professionally prescribed medication drugs. We recommended that the government should play an active role in resourcing the mandated institutions in the dispensation of medication drugs, to eliminate the proliferation of the activities of medication drug hawkers.
\end{abstract}

Keywords: Bus passengers' perception, medication drug hawking, intercity

DOI: $10.7176 / \mathrm{JMCR} / 57-06$

Publication date:June $30^{\text {th }} 2019$

\section{INTRODUCTION}

Drug Hawking is a universal and mounting urban menace in West African (Tinker, 2003). It forms an integral and important part of the formal economic sector of West African countries. Hawking is highly patronized because it provides affordable services to low income families since it often retails products to them instead of in bulk (Davis, 2008). In Nigeria, hawking can be found in all major cities and covers almost all products including pharmaceuticals goods. For instance, anyone can buy drugs from vendors in buses without a doctor's prescription or pharmacist assistance.

People who are involved in this trade are known as drug hawkers or vendors. Drug hawkers move from one place to another; as such the drugs are subjected to varying degree of harsh environmental conditions. They are mostly seen in public places like motor parks, worship centres, social functions as well as major streets in the Nigeria (Akintayo and Braide, 2013).

Drug hawking provides avenue for drug counterfeits to market their dangerous products to the public away from the eyes of regulatory agencies like National Drug Law Enforcement Agency (NDLEA). The potency of drugs sold in open places, especially on mass transit buses in cities is uncertain because such drugs being exposed to extreme temperatures may have lost their efficacy. 
The commercial drivers, commercial motorcyclists and motor park touts are in the habit of buying various forms of drugs promoted by hawkers in commercial buses. The bus passengers are not left out. They patronize it for the purpose of pain relief (NAFDAC [National Agency for Food and Drug Administration and Control] 2014) it has been asserted that individuals patronizing drug hawkers are engaging in a suicide mission and the assertion that genuine pharmacies and hawkers sell the same drugs is not true.

However, there is need for people to patronize authorized pharmaceutical outlets or chemists as the case may be for the purchase of genuine drugs (Jimoh \& Liya 2014). The federal government of Nigeria through the NAFDAC stated that drug hawking is an illegal business and offenders are liable to be charged to court. Drug hawking is an aberration that should be discouraged by everyone. There appears no reason why people should patronize drug hawkers in commercial buses, however, even if the drugs sold were originally potent and efficient by the time they were exposed to harsh weather conditions, their safety cannot be guaranteed since their ideal storage conditions was not met.

Many passengers have testified that drugs gotten from hawkers in commercial buses did not only provide avenue for drug counterfeiters to market dangerous products to the unsuspecting public but also have sent many people to their early graves or misinformed many. NAFDAC has repeatedly condemned the menace of drug hawking in motor parks and buses and emphasized that medication drugs should only be purchased from registered dispensaries or pharmacy stores.

Geographic and economic access to safe efficacious and affordable essential medication of good quality is predicated on a well structured and properly regulated medicines distribution system. This is particularly important in the public sector which caters for the majority of the populace in dispensing medication drugs.

Health services have been severely hampered in Nigeria by acute shortage of essential medicines for many years. Hence, health care coverage is perennially low with less than $30 \%$ having regular access to essential medicines, particularly in the public sector. The majority of Nigerians have been, willy-nilly, driven to the private sector to meet their medication needs due to non availability of essential medicines at public health facilities. As a result of this, many Nigerians prefer buying drugs from hawkers in commercial buses (Yusuf \& Sanni, 2011).

In Nigeria, especially in the Southeast, despite the legal implications of drug hawking, the business continues to proliferate. The factors responsible for this situation need to be understood. Many Nigerians seem to have a penchant for shortcuts in getting medicines; often times, this shortcut is dangerous to them.

\section{STATEMENT OF THE RESEARCH PROBLEM}

In-vehicle medication drug hawking and the consumption of such drugs raises some consumer-health safety questions. This is in the light of the production and distribution of counterfeit medication drugs having become a significant global public health issue (Law and Youmans, 2011: 114). Despite the assertions made by different researchers over this trend, including the responses of most people; yet many Nigerians still patronize drug hawkers on inter-city commercial buses. What could be the implications of this situation to the wellbeing of people who patronize these medication drug vendors?

\section{OBJECTIVE OF THE STUDY}

We examined the intercity bus passengers' perception and response to in-vehicle medication drug hawking using some selected commercial buses taking off from Onitsha commercial city. Against this backdrop, this study sought answers to the following questions:

1. How exposed are intercity bus passengers in Onitsha commercial city to in- vehicle medication drug hawking?

2. Are these passengers convinced to purchase in-vehicle vended medication drugs as a result of how they been promoted by in-vehicle vendors?

3. How aware are these bus passengers of the risk associated with using purchased vended medication drugs? hawking?

4. What are the factors that influence the patronage of vended medication? 


\section{LITERATURE REVIEW}

The dynamics of how medication drug consumers are influenced by drug hawking must be preceded by the need to define drug hawking.

\subsection{The Nature of Drug Hawking}

According to Pandya (1988), drug hawking is an illegal act of selling drugs in a transparent plastic basket with some of the drugs hanged around and crossing the terminals of the basket. It becomes obvious that the practice of selling drugs in the open place has not only affected the general efficacy of drugs by exposing them to extreme temperatures that make them expire early, but it has also provided avenue for drug counterfeits to market their dangerous products to an unsuspecting public.

The poison and pharmacy act (ppa) cap 366 of 1990 regulates the supply, distribution and sale of medicines in static outlets that are duly registered by the Pharmacist Council of Nigeria. The act clearly prohibits the display, distribution and sale of all categories of medicines in unregistered outlets. Many Nigerians are aware of this drug hawking, especially in buses, and are constantly influenced by the strategies of the drug hawkers who assure the buyers that by patronizing their drugs, their problems are instantly solved.

According to Milan (1987), drug hawking refers to "a sure death forum used by drug vendors through illegal selling of drugs at public places such as buses, streets, stores etc." The study emphasized that the problem with self medication is either the drug seller or the consumer is unaware of the correct dosage and duration of treatment.

World Health Organization (WHO, 1985) refers to drug hawking as an illegal act of selling drugs unregistered to the desperate public.

Many studies have investigated the potential threat to well being associated with drug hawking business among Nigerian travelers, especially on buses. In one of the studies of management sciences for health, Arya (1995) posited that vended drugs in developing countries show that large proportion of drugs are of low quality. This is partly because these drugs are constantly exposed to dust, sun and changes in the weather.

Roy (1994) holds that the effects of these low quality drugs include treatment failure and serious damage to the patients' health or even death. A study by the World Health Organization cited by Law and Yowmans (2011) indicated 771 reports of counterfeit medications between 1984 and 1999, of which $78 \%$ originated in developing countries.

\subsection{Prevalence of Drug Hawking in Nigeria}

It is typical to see drugs sold openly as if they are common merchandize like clothes and cosmetics in most Nigerian markets. This attitude betrays an acute lack of understanding of the nature of drugs and the obvious fact that those peddling them are not professionals who are authorized to handle such sensitive products. But the practice has continued to thrive nevertheless; aided in part by the patronage of the public who have indirectly continue to sustain the practice.

It has been asserted that individuals patronizing drug hawkers are engaging in a suicide mission. Drug hawking is an aberration that should be discouraged. There appears no reason why people should patronize drug hawkers, however, even if the drugs sold by the hawkers were originally potent and efficient, by the time they were exposed to harsh weather conditions, their safety cannot be guaranteed since their ideal storage condition is negated.

Jimoh and Liya (2014) posited that the storage temperatures (not more than $25-30^{\circ} \mathrm{C}$; or, $2-8^{0} \mathrm{C}$ for drugs that should be refrigerated) are a major determinant in the maintenance of potency, efficacy and stability of all drugs. Notwithstanding all the plethora of laws, drug hawking remains pervasive in Nigeria. This phenomenon is probably fueled by inadequate drug regulatory capacity and ineffectual enforcement of the pharmaceutical laws regulating the distribution and sales of medicines.

Buying medications for their health needs in buses has become a popular past time of many Nigerians. Many Nigerians want to have a shortcut which is to their own detriment. Drugs can heal and kill. Various studies done by different scholars recorded that many had gone through in-take of drugs illegally. The human development index (HDI 2011) attributes about $15 \%$ of deaths in Nigeria to wrongly prescribed medications and expired drugs. This shows the level of damage of illegal drug business in the country.

\subsection{Factors Contributing to High Level of Patronage of Drug Hawking in Nigeria}

Vended medicines could have their public health consequences in a developing setting like Nigeria where irrational self medication with prescription only medicines, over the counter medicines (OTC) and herbal remedies of both known and unknown contents, poorly guided self medication practices have been shown to provoke adverse drug 
reactions, delay or mask diagnosis of a serious underlying medical problem and increase the risk of potentially harmful dry drug or drug- disease interactions. This unbridled drug use habit among Nigerians has been linked to series of factors. These factors include:

First, the peculiar health-seeking behavior which favours self medication as the first response to perceived health problems, and uncontrolled access patients have to both orthodox and herbal medicines in Nigeria. A study on over the counter and prescription drugs found in places such as the streets and open markets, including buses may be of lower quality since they are often not well regulated. For instance low level products( patent medicine vendors) accounted for $78 \%$ of suspect medicines in Onwujekwe (2009); and $90 \%$ of medicines found to be substandard in Tipke (2009) were obtained from illicit outlets.

Second, majority of Nigerians have been willy-nilly driven to the private sector to meet their medicine needs due to poor availability of essential medicines at public health facilities. However, this shift has worsened economic access, as payment for medicines purchase is generally done out of pocket in the private sector in Nigeria. In deed out of pocket payment for medicines in the private sector constitutes a significant part of the pharmaceutical expenditure (WHO/DA 198.3 1998). Hence, majority of Nigerians who lived below the poverty line of less than 1 USD per day are experiencing financial difficulty in meeting their basic needs including essential medicines (Ogunbekum \& Orobaton, 1999).

Third, the extensive direct-to-consumer advertising of over the counter medicines which is focused on positive emotional appeals but contains insufficient educational information which may be misleading, have been reported by previous studies in Nigeria (Yusuf, 2009). Paracetamol and Non-Steroidal Anti-Inflammatory Drugs (NSAIDS) were mainly promoted as powerful painkillers that will provide instant relief from musco-skeletal and joint pains experienced by drivers, bus conductors, traders, artisans, passengers in commercial buses who regularly travel by bus. The attainment of increased body weight and light smooth skin which are culturally perceived as sign of good living and well-being, were the dominant themes used for sales of prescription alone medicine.

Fourth, the drug hawkers use standard strategies to influence the consumers. Multivitamins were presented as good substitute for balanced diets which may not be affordable for the majority of consumers who appeared specifically targeted inside commercial buses and provide them with essential vitamins and minerals that their current diet may not be providing. Hermatinics were promoted by drug hawkers as purifiers and cleansers of the circulatory system that will remove dirt and impurities. Elijah Mohammed, Registrar of the council of the Pharmacists Council of Nigeria $(\mathrm{PCN})$ vowed to eradicate open drug hawking in Nigeria.

Fifth, illiteracy contributes to spontaneous patronage of vended drugs in buses. The freedom in which drug hawking and patronage takes place suggests a strong and successful bonding between vendors and the consuming population. The bonding appeared strong enough for consumers to patronize and trust the vendor for their medical needs without as much as ascertaining their capability and competency to discharge the trust appropriately (Yusuf \& Sanni, 2011).

\section{THEORETICAL FRAMEWORK}

This work was predicated on the theoretical postulations of Hochbaum, Rosenstock and Kegels (1950): The Health Belief Model (HBM).

Since the emergence of drug hawking in buses, Nigerians have become predisposed to patronize vended medication drugs without caring for its dosage or after effect. This model as applied in this study focused on the attitudes and beliefs of individuals, especially on health issues.

\subsection{Health Belief Model}

The health Belief model was spelt out in terms of four constructs: Perceived susceptibility, perceived severity, perceived benefits and perceived barriers.

These concepts were proposed as accounting for people's readiness to act. A recent addition to the HBM is the concept of self efficacy, or one's confidence in the ability to successfully perform an action (Rosenstock, 1974).

This presupposes that the present high rate of patronage of in-vehicle drug hawking affects individual health behaviours as well as creates more room for danger to the society if not legally tackled. Simply put, this model is relevant to this study because frequent patronizing of illegal drugs at public places, consumers perception and reactions of those drugs on them, is a product of health beliefs.

Thus, the underlying assumptions of this model are: 
- Readiness to prevent health behavior, which includes health promotion, health risk behavior, as well as vaccination and contraceptive practices.

- Sick role behaviours, which refer to compliance with recommended medical regimes.

- Clinic use, which includes physician visits for a variety of reasons.

\section{RESEARCH METHODOLOGY}

The survey research method was employed in this study. The population comprised the total number of inbound passengers, 36,680 who transited through two major parks (Peace Park and Lagos Park) in Onitsha commercial city, within the period of this study, according to the records obtained from the authorities at these parks. These parks had been purposively chosen because they boast the largest volumes of transiting passengers per day.

In choosing the sample size, we looked at the suggestions of Comrey (1973) which hold that for a multivariate study, a sample size of 300 is good. We therefore adopted 300 as our sample size.

A structured interview was used to elicit responses to our questions based on volunteer sampling technique.

\section{DATA ANALYSIS}

Results from our data show that, $184(61.3 \%)$ of our respondents are males and $116(38.7 \%)$ females; $174(58 \%)$ of the respondents are aged between 18 yrs to 45 years; $106(35.3 \%)$ are aged between 46 yrs and 60 years, and $20(6.7 \%)$ are aged above 61 years.

In examining respondents type of employment, our finding indicate that majority of our respondents are self employed, 157 (52.3\%); 102 (34\%) are government-employed and the remaining $41(13.7 \%)$ are employed in the private sector. On the respondents level of education, majority hold O' level certificate (104-34.7\%), followed by Diploma $(74.24 .7 \%)$, post graduate $(43,14.3 \%)$, under graduate $(32,10.7 \%)$, other qualifications cater for the remaining $47(15.6 \%)$.

Table 1: Respondents who have been exposed to in-vehicle medication drug hawking

\begin{tabular}{|l|l|l|l|}
\hline & $\begin{array}{l}\text { Respondents who have been exposed to in- } \\
\text { vehicle medication drug hawking }\end{array}$ & Frequency & Percentage \\
\hline i & Yes & 269 & $90 \%$ \\
\hline ii & No & 31 & $10 \%$ \\
\hline & & 300 & $100 \%$ \\
\hline
\end{tabular}

Data in Table 1 shows that a greater percentage of the respondents (90\%) have been exposed to in-vehicle medication drug hawking. Te percent, however, said they have not been exposed to such hawking. The picture here is that in-vehicle medication drug hawking appears to be widespread.

Table 2: Respondents who purchased vended medicines

\begin{tabular}{|l|l|l|l|}
\hline A & Ever patronized vended drug & Frequency & Percentage \\
\hline i & Yes & 232 & $77.3 \%$ \\
\hline ii & No & 68 & $22.7 \%$ \\
\hline & & 300 & $100 \%$ \\
\hline
\end{tabular}

Table 2 shows that majority of the respondent $232(77.3 \%)$ indicated that they have patronized in-vehicle medication drug vendors and the remaining 68 (22.7\%) indicated they did not. A qualitative analysis of reasons for non purchase shows that more of the respondents indicated that they perceived the vendors as very deceitful; others dwelt on the perception that the vended drugs were fake ones. 
Table 3: Respondents ever assess the quality of medicine purchased and if they are aware of the risk associated with its usage.

\begin{tabular}{|l|l|l|l|}
\hline A & Assessment of quality of drug patronize after usage & Frequency & Percentage \\
\hline i & Very good & 53 & $22.7 \%$ \\
\hline ii & Good & 37 & $15 . \%$ \\
\hline iii & Non committal & 23 & $9.9 \%$ \\
\hline iv & Bad & 57 & $24.6 \%$ \\
\hline v & Very bad & 232 & $78 \%$ \\
\hline B & $\begin{array}{l}\text { Awareness of Risks associated in the purchased vended } \\
\text { drugs }\end{array}$ & Frequency & Percentage \\
\hline i & Yes & 207 & $89.2 \%$ \\
\hline ii & No & 25 & $10.8 \%$ \\
\hline & & 232 & $100 \%$ \\
\hline
\end{tabular}

Table 3 shows how the respondents assessed the quality of vended drugs they purchased after usage. A greater percentage (78\%) assessed the vended drugs as being very bad; while $22.7 \%$ indicated they were very good. Similarly, 89.2 percent of the respondents were aware of the risks associated with purchased vended drugs; while $25 \%$ were not.

Table 4: Factors that influence the patronage of vended drugs

\begin{tabular}{|l|l|l|l|l|l|l|}
\hline SN & Factors & SA & A & Neutral & Disagree & SD \\
\hline a. & Time spent at hospital & 58.1 & 27.8 & - & 10 & 4.1 \\
\hline b & Level of education & 15.7 & 9.6 & 4.3 & 50.2 & 20.2 \\
\hline c & Level of information & 35.7 & 28.9 & - & 33.4 & - \\
\hline d & $\begin{array}{l}\text { Accessibility of healthcare } \\
\text { facilities }\end{array}$ & 45.4 & 19.2 & 2.1 & 22.2 & 11.1 \\
\hline e & Cost of medical delivery & 36.1 & 16.3 & 5.6 & 22.7 & 19.3 \\
\hline f & Weak institutions and regulations & 31.7 & 44.1 & 0.2 & 9.4 & 14.6 \\
\hline
\end{tabular}

Table 4 depicts the factors that influence the patronage of vended medicines. A greater number among the respondents claimed that time spent at hospitals $(84.9 \%)$ was the main reason the patronized vended medication drugs, $66.6 \%$ pointed to level of information dissemination by authorities; $(52.4 \%)$ said accessibility to health care facilities and shops was the reason. The cost of medical delivery was claimed by $75.8 \%$ of the respondents as the reason for the purchase of vended medication drugs. However, $70.4 \%$ of the respondents disagreed that their level of education had any influence on their decision to purchase vended drugs. Equally, $54.8 \%$ also disagreed that they are not influenced by weak health institutions and regulations.

\section{CONCLUSION}

This study examined the perceptions and response of intercity bus passengers to medication drug hawking using some selected inbound passengers of major parks in Onitsha commercial city, Nigeria. The study discovered that the practice of medication drug hawking is high because of the patronage hawkers receive from intercity bus passengers. This activity remains pervasive despite its prohibition by relevant laws. This appears to be so, as revealed in the study, owing to the apparent inhibitions experienced by the respondents when they attempt to get doctor's examination and prescription. Similarly, the lack of available health facilities in some cases and the lack of the will by concerned agencies to enforce the law prohibiting medication drug hawking, have in so ways sustained the practice of in-vehicle medication drug hawking. 


\section{RECOMMENDATIONS}

In the light of the findings of this study we recommended the following measures:

- That the government should reform and mandate relevant health institutions and agencies charged with enforcing public health safety law to function.

- There should be a sustained communication intervention to educate the citizenry on way they should purchase medicine only from registered sources according to doctors' prescription.

- There should be an arrangement by concerned agencies to liaise with intercity commercial bus owners and drivers to check and discourage in-vehicle medication drug hawking.

\section{REFERENCES}

Akintayo, O. and Braide, I. (2013) Marketing Research: An Applied Approach, Prentice- Hall, Harlow.

Arya, S.C. (1995), Itinerant supply of substandard Drugs. Word Health Form 16, 269.

Comrey, A. L. (1973). A first course in factor analysis. New York, NY: Academic Press.

Davis, J. (2008), Selling Wares on the Streets of Accra: A Case Study of Street Hawkers in Ghana's Capital. Focus on Geography, 51(3):32-36

Food and Drug Act, Cap 150. Abuja, Nigeria: Federal Government of Nigeria. 1990.

Jimoh and Hiya (2014). Death for sale: A study of Drug poisoning and Deaths in Nigeria. Social Science and Medicine, 38(1):97-103.

Law, E and Youmans L.S. (2010). Combating Counterfeit Medications: The califernia pharmacist perspective. Journal of Pharmacy practice. 24(1):114-121.

Milan, M.M. (1989). Docters Blame fake medicines for Deaths. The Sunday Times, 1November 15.

National Agency for food and Drug Administration and Control Decree No. 15. Abuja, Nigeria: Federal Government of Nigeria. 2014.

Ogunbeku, A. \& Orobaton, N. (1999). Private health care in Nigeria: walking the tightrope, Health Policy Plan. 1999 Jun;14(2):174-81

Onwujekwe, et al (2009) Quality of anti- malaria drugs provided in public and private healthcare providers in south east Nigeria. Malaria, formal, 8 (20): 1-9.

Pandya, S. K. (1988). An unmitigated tragedy, British medical journal 297, 117-119

Rosenstock IM: Historical origins of the health belief model, Health Education Monographs 2:328-335, 1974.

Roy, J. (1994) The menace of substandard drugs. World Health Forum15, 406-407

Tipke, M., Diallo, S., Coulibaly, B., Störzinger, D., Hoppe-Tichy, T., Sie, A and Müller, O (2009). Substandard Anti-Malarial Drugs in Burkina Faso. Malaria Journal 7: 95

Tinker, I. (2003), Street Foods: Traditional Micro-Enterprise in a Modernizing World. International Journal of Politic, Culture and Society, 16(3): 331-349.

Yususf, K. B. \& Yusuf A. (2009). Advertising OTC medicines in a Nigerian urban setting: content analyses for indications, targets and advertising appeals. J. Am Pharm. Assoc. 2009. 49,86-89. (Pub Med)

Yusuf, K.B. \& Sanni A. (2011). Itinerant vending of medicines inside buses in Nigeria: vending strategies, dominant themes and medicine-related information provided, Pharm Pract Granada; 9(3); 128-135

World Health Organization Special issue 14 pp. 4-6 